\title{
Pregnancy related and postpartum admissions to intensive care unit in the obstetric tertiary care center - an 8-year retrospective study
}

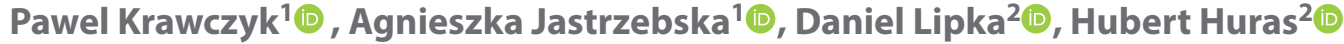 \\ ${ }^{1}$ Department of Anesthesiology and Intensive Care Medicine, Jagiellonian University Medical College, Cracow, Poland \\ ${ }^{2}$ Department of Obstetrics and Perinatology, Jagiellonian University Medical College, Cracow, Poland
}

\begin{abstract}
Objectives: The purpose of the study was to analyze the incidence of maternal morbidity and mortality of pregnant and postpartum women admitted to the intensive care unit (ICU).

Material and methods: Retrospective analysis of all pregnant and postpartum patients admitted to ICU of the obstetric tertiary care center between January 1, 2007 and December 31, 2014.

Results: A total of 266 patients with pregnancy and postpartum related morbidity were admitted to ICU (12.56 per 1000 deliveries). It accounted for $21.08 \%$ of all adult admissions of the unit. Mean age was $30.2 \pm 5.6$ years, mean gestational age was $30.8 \pm 7.6$ weeks. Two hundred forty patients (90.23\%) were primiparous, 17 (6.4\%) were twin pregnancy. Main reasons of admission included hypertensive disorders of pregnancy $n=99$ (37.22\%; 4.68 per 1000 deliveries), hemorrhage $n=46$ (17.29\%; 2.17 per 1000 deliveries) and sepsis/infection $n=46$ (17.29\%; 2.17 per 1000 deliveries). Median length of stay was five days (IQR 4-7). Artificial ventilation was required in 91 patients (34.21\%), 147 (55.26\%) required vasoactive drugs, 33 (12.41\%) had metabolic disturbances, 21 (7.89\%) required total parenteral nutrition and $4(1.50 \%)$ renal replacement therapy. We report four maternal deaths (1.5\%; 0.19 per 1000 deliveries).

Conclusions: There are three main reasons of obstetric ICU admissions: hypertensive disorders of pregnancy, obstetric hemorrhage and sepsis/infection. The majority of obstetric patients admitted to ICU did not require multi-organ supportive therapy. Availability of intermediate care facility could reduce unnecessary admission to ICU.
\end{abstract}

Key words: maternal morbidity; maternal mortality; maternal critical care; intensive care unit

Ginekologia Polska 2021; 92, 8: 575-578

\section{INTRODUCTION}

Severe maternal morbidity despite rare incidence in developed countries may have catastrophic consequences and has significant influence on maternal mortality [1, 2]. Pregnancy related admissions to an intensive care unit (ICU) usually include patients in the most serious conditions. However, many of these patients are managed within obstetric units. It may result in relative underreporting the incidence of severe maternal morbidity.

\section{Objectives}

The purpose of the study was to analyze basic characteristics and incidence of maternal morbidity and mortality as well as medical interventions undertaken in pregnant and postpartum women admitted to ICU of the obstetric tertiary care center.

\section{MATERIAL AND METHODS}

After receiving approval from the Ethics Committee of Jagiellonian University, Cracow, Poland (approval number: 122.6120.41.2015) and institutional approval, we conducted a retrospective study including all pregnancy related ICU admissions from the obstetric tertiary care center (Jagiellonian University Hospital Cracow, Poland) between January 1, 2007 and December 31, 2014.

The obstetric tertiary care center was one of forty Polish obstetric tertiary care centers with 76 obstetric beds, four-bed ICU and an annual number of about 3000 births.

\footnotetext{
Corresponding author:

Pawel Krawczyk

Department of Anesthesiology and Intensive Care Medicine, Jagiellonian University Medical College, Cracow, Poland

e-mail: p.krawczyk@uj.edu.pl
}

This article is available in open access under Creative Common Attribution-Non-Commercial-No Derivatives 4.0 International (CC BY-NC-ND 4.0) license, allowing to download articles and share them with others as long as they credit the authors and the publisher, but without permission to change them in any way or use them commercially. 
It covers the population of 3410900 inhabitants with annual number of 36900 births [3].

The following data were obtained for each patient: demographics, obstetrical history, medical ICU interventions (respiratory support, vasoactive drugs use, renal replacement therapy, diuretic use, invasive pulmonary artery monitoring, total parenteral nutrition use, need for resuscitation, presence of metabolic disturbances) and length of stay in ICU.

Descriptive data are presented as means \pm standard deviation (SD) and median value with interquartile range (IQR) for continuous variables and as percentages (\%) for categorical variables. Analyses were conducted using $\mathrm{R}$ software (ver. 3.5.1; R Development Core Team, Austria, Vienna) [4].

\section{RESULTS}

A total of 266 patients with pregnancy related morbidity were admitted to ICU (12.56 per 1000 deliveries). It accounted for $21.08 \%$ of all adult admissions of ICU. Mean age was $30.2 \pm 5.6$ years, mean gestational age was $30.8 \pm 7.6$ weeks. There were 20 (7.52\%) patients admitted during pregnancy $\leq 20$ weeks of gestation. Two hundred forty patients (90.23\%) were primiparous, 17 (6.4\%) were twin pregnancy. The main reasons of admission included hypertensive disorders of pregnancy $n=99$ (37.22\%; 4.68 per 1000 deliveries), hemorrhage $n=46(17.29 \% ; 2.17$ per 1000 deliveries), sepsis/infection $n=46$ (17.29\%; 2.17 per 1000 deliveries). Detailed results are presented in Table 1. Median length of stay was five days (IQR 4-7).

Table 1. Reasons of intensive care unit admission

\begin{tabular}{|c|c|c|c|c|}
\hline & & & & \\
\hline Hypertensive disease & HELLP syndrome & 17 & 6.39 & 0.8 \\
\hline & Eclampsia & 15 & 5.64 & 0.71 \\
\hline & Hemorrhagic stroke & 3 & 1.13 & 0.14 \\
\hline & & 46 & 17.29 & 2.17 \\
\hline Obstetric hemorrhage & Abnormal placentation & 16 & 6.01 & 0.75 \\
\hline & Hysterectomy & 7 & 2.63 & 0.33 \\
\hline & & 46 & 17.23 & 2.17 \\
\hline 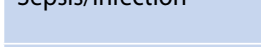 & Hysterectomy & 4 & 1.5 & 0.19 \\
\hline & & 23 & 8.65 & 1.09 \\
\hline & Valvular heart disease & 13 & 4.89 & 0.61 \\
\hline & Cardiomyopathy & 4 & 1.5 & 0.19 \\
\hline Laturac uisease & Pulmonary hypertension & 3 & 1.13 & 0.14 \\
\hline & Arrhythmia & 2 & 0.75 & 0.09 \\
\hline & Marfan syndrome & 1 & 0.37 & 0.05 \\
\hline Thromboembolism & & 12 & 4.51 & 0.57 \\
\hline & & 40 & 15.04 & 1.89 \\
\hline & Pulmonary edema & 11 & 4.13 & 0.52 \\
\hline & OHSS & 5 & 1.88 & 0.24 \\
\hline & End-stage renal insufficiency & 4 & 1.5 & 0.19 \\
\hline & Systemic lupus erythematosus & 4 & 1.5 & 0.19 \\
\hline & Malignancy during pregnancy & 5 & 1.88 & 0.24 \\
\hline Miscellanenus & Status epilepticus & 2 & 0.75 & 0.09 \\
\hline - & Myasthenia & 2 & 0.75 & 0.09 \\
\hline & Anesthesia complications & 2 & 0.75 & 0.09 \\
\hline & Porphyria & 1 & 0.38 & 0.05 \\
\hline & Pancreatitis & 1 & 0.38 & 0.05 \\
\hline & Epistaxis & 1 & 0.38 & 0.05 \\
\hline & Hemolytic Uremic Syndrome & 1 & 0.38 & 0.05 \\
\hline & Hyperemesis gravidarum & 1 & 0.38 & 0.05 \\
\hline
\end{tabular}




\begin{tabular}{|l|l|l|l|l|l|l|}
\hline \multicolumn{3}{|l|}{ Table 2. Medical interventions in intensive care unit } \\
\hline
\end{tabular}

Artificial ventilation was required in 91 patients (34.21\%), 147 (55.26\%) required vasoactive drugs, 33 (12.41\%) had metabolic disturbances, 21 (7.89\%) required total parenteral nutrition and only four (1.50\%) renal replacement therapy. Detailed results of the interventions are presented in Table 2. We report four maternal deaths (1.5\%; 0.2 per 1000 deliveries).

\section{DISCUSSION}

Results of this study show that in eight-year review obstetric patients admitted to ICU represented $1.26 \%$ of all deliveries and accounted for $21.08 \%$ of all ICU admissions. It is comparable with other studies reporting ICU admission rate of 0.7-4.2 per 1000 deliveries [5-9]. Several factors contribute to this: specific profile of the obstetric care tertiary center, easy access to ICU, hospital ICU admissions of women after birth elsewhere and lack of high dependency unit $[10,11]$. The percentage of obstetric ICU admissions corresponds with severe maternal morbidity of $1-3 \%$ of all deliveries [12-14].

Our study indicates that one-third of ICU obstetric patients suffered from hypertensive disease of pregnancy. It is comparable to data described in relevant literature [11]. However, the range of frequency of the disease is higher ranging from 6 to 63 percent [2]. The subgroup analyses revealed similarly to other studies incidence of HELLP syndrome, severe pre-eclampsia and eclampsia [15]. Pregnancy related hemorrhagic stroke is relatively rare complication of pregnancy 12.2 per 100000 pregnancies [16]. In our study it occurred in three patients representing $1.13 \%$ of the study population with incidence of 0.14 per 1000 deliveries.

We found 46 patients (17.29\%) with an obstetric hemorrhage as a reason for ICU admission. It was lower than reported in other studies from developed countries (32.5\%) [5]. However, this may result from incomplete reporting of maternal hemorrhage since many of the bleeding obstetric patients are treated in post-anesthesia care units close to an operating room [2].

Sepsis/infection was reported in 46 patients (17.29\%) with incidence 2.17 per 1000 deliveries. Infections and sepsis in large ICU obstetric population studies are responsible for approximately 5\% ICU admissions [5]. Studies involving smaller groups report wider range of this reason for ICU admission 1-97\% [2]. In developed countries obstetric sepsis occurs in 29-47 per 100000 pregnancies [17, 18]. The increase in percentage of patients with sepsis/infection admitted to the ICU was related to hospital ICU admissions to the tertiary obstetric care center of women after birth elsewhere.

In the current study, we were able to identify 23 (8.65\%; 1.09 per 1000 deliveries) patients admitted to ICU due to cardiac disease. Other studies report higher percentage of ICU admissions due to cardiac disease even up to $21 \%[6,9]$. This may suggest better antenatal care of obstetric patients with cardiac disease allowing to avoid ICU admissions.

Thromboembolic disorder was the reason of ICU admission of 12 patients (4.51\%). Published evidence indicate similar incidence of thromboembolism in pregnancy $2.8-5 \%$ $[10,11,19]$.

We found 40 patients with other reasons of ICU admissions. In this group the most numerous diagnosis was pulmonary edema present in 11 patients (4.13\%). This is a common disorder with different origin in course of pregnancy and puerperium [20].

In our study we report four maternal deaths $(1.5 \%$; 0.19 per 1000 deliveries). It corresponds with similar data from major population-based studies reporting maternal death following ICU admission rate of $0.3-3.5 \%[5-9,19]$ and incidence of 0.05-0.11 per 1000 deliveries [2].

In Poland, maternal mortality rate in 2017 was two per 100000 live births and it has significantly decreased in the 
past few decades. Poland has $71 \%$ of overall reduction in maternal mortality rate between 2000 and 2017 [21].

In our study we observed only one-third of obstetric patients admitted to the ICU requiring artificial ventilation. Very common interventions included use of vasoactive drugs ( 147 cases; $55.26 \%$ ) and diuretics (203 cases; $76.32 \%$ ). Thirty-three patients (12.36\%) had metabolic disturbances and $21(7.87 \%)$ required total parenteral nutrition. Only four patients $(1.5 \%)$ required renal replacement therapy. No patient required pulmonary artery catheter or equivalent advanced monitoring. Mean duration of ICU stay was five days. The results suggest lower ICU disease severity in obstetric patient population when compared to other ICU population what was also observed in other studies [6]. In order to reduce number of obstetric ICU admissions many strategies may be undertaken including risk factors identification and their modification, meticulous evaluation of comorbidities and guidance for impact of pregnancy on the disease, pre-conception counselling and proper perinatal service, availability of multidisciplinary expert consultation [2].

The study has several limitations. It was retrospective single center study. The tertiary care center admissions are related to pregnancy complications from regional hospitals what may influence on reported maternal morbidity and mortality rates. We analyzed epidemiology and ICU interventions without postpartum long-term outcome, psychological sequel and neonatal outcome which are out of scope of the manuscript.

\section{CONCLUSIONS}

There are three main reasons of obstetric ICU admissions. Hypertensive disorders of pregnancy, obstetric hemorrhage and sepsis/infection. Improving antenatal care may help to reduce obstetric ICU admission rate. Maternal mortality was similar to reports in other studies from intensive care units. Majority of obstetric patients admitted to ICU did not require multi-organ supportive therapy. Availability of intermediate care facility could reduce unnecessary admission to the ICU.

\section{Conflict of interest}

None.

\section{REFERENCES}

1. MBRRACE-UK - Saving Lives, Improving Mothers' Care 2019. https:// www.npeu.ox.ac.uk/assets/downloads/mbrrace-uk/reports/MBRRACE-UK\%20Maternal\%20Report\%202019\%20-\%20WEB\%20VERSION. pdf (27.09.2020).

2. Einav S, Leone M. Epidemiology of obstetric critical illness. Int J Obstet Anesth. 2019; 40: 128-139, doi: 10.1016/j.ijoa.2019.05.010, indexed in Pubmed: 31257034 .

3. Ludność w województwie Małopolskim. Urodzenia w województwie Małopolskim. https://krakow.stat.gov.pl/ (27.09.2020).
4. R Core Team. A language and environment for statistical computing. R Foundation for Statistical Computing, Vienna, Austria. https:// www.R-project.org/ (27.09.2020).

5. Pollock W, Rose L, Dennis CL. Pregnant and postpartum admissions to the intensive care unit: a systematic review. Intensive Care Med. 2010; 36(9): 1465-1474, doi: 10.1007/s00134-010-1951-0, indexed in Pubmed: 20631987.

6. Chantry AA, Deneux-Tharaux C, Bonnet MP, et al. Pregnancy-related ICU admissions in France: trends in rate and severity, 2006-2009. Crit Care Med. 2015; 43(1): 78-86, doi: 10.1097/CCM.0000000000000601, indexed in Pubmed: 25377016.

7. Oud L. Epidemiology of Pregnancy-Associated ICU Utilization in Texas: 2001 - 2010. J Clin Med Res. 2017; 9(2): 143-153, doi: 10.14740/jocmr2854w, indexed in Pubmed: 28090230.

8. Zwart JJ, Dupuis JRO, Richters A, et al. Obstetric intensive care unit admission: a 2-year nationwide population-based cohort study. Intensive Care Med. 2010;36(2): 256-263, doi: 10.1007/s00134-009-1707-x, indexed in Pubmed: 19902177.

9. Wanderer JP, Leffert LR, Mhyre JM, et al. Epidemiology of obstetric-related ICU admissions in Maryland: 1999-2008*. Crit Care Med. 2013; 41(8): 1844-1852, doi: 10.1097/CCM.0b013e31828a3e24, indexed in Pubmed: 23648568

10. Mirghani HM, Hamed M, Ezimokhai M, et al. Pregnancy-related admissions to the intensive care unit. Int J Obstet Anesth. 2004; 13(2): 82-85, doi: 10.1016/j.ijoa.2003.10.004, indexed in Pubmed: 15321409.

11. Keizer JL, Zwart JJ, Meerman RH, et al. Obstetric intensive care admissions: a 12-year review in a tertiary care centre. Eur J Obstet Gynecol Reprod Biol. 2006; 128(1-2): 152-156, doi: 10.1016/j.ejogrb.2005.12.013, indexed in Pubmed: 16443319

12. Female admissions (aged $16-50$ years) to adult, general critical care units in England, Wales and Northern Ireland reported as 'currently pregnant' or 'recently pregnant'. 1 January 2009 to 31 December 2012. https://www.oaa-anaes.ac.uk/assets/_managed/cms/files/Obstetric\%20 admissions\%20to\%20critical\%20care\%202009-2012\%20-\%20FINAL. pdf (27.09.2020).

13. Lazariu V, Nguyen T, McNutt LA, et al. Severe maternal morbidity: A population-based study of an expanded measure and associated factors. PLoS One. 2017 ; 12(8): e0182343, doi: 10.1371/journal.pone.0182343, indexed in Pubmed: 28787028.

14. Leovic MP, Robbins HN, Starikov RS, et al. Multidisciplinary obstetric critical care delivery: The concept of the "virtual” intensive care unit. Semin Perinatol. 2018; 42(1): 3-8, doi: 10.1053/j.semperi.2017.11.002, indexed in Pubmed: 29310986.

15. Demirkiran O, Dikmen Y, Utku T, et al. Critically ill obstetric patients in the intensive care unit. Int J Obstet Anesth. 2003; 12(4): 266-270, doi: 10.1016/S0959-289X(02)00197-8, indexed in Pubmed: 15321455.

16. Swartz RH, Cayley ML, Foley N, et al. The incidence of pregnancy-related stroke: A systematic review and meta-analysis. Int J Stroke. 2017; 12(7): 687-697, doi: 10.1177/1747493017723271, indexed in Pubmed: 28884652.

17. Oud L, Watkins P. Evolving trends in the epidemiology, resource utilization, and outcomes of pregnancy-associated severe sepsis: a population-based cohort study. J Clin Med Res. 2015; 7(6): 400-416, doi: 10.14740/jocmr2118w, indexed in Pubmed: 25883702.

18. Acosta CD, Kurinczuk JJ, Lucas DN, et al. United Kingdom Obstetric Surveillance System. Severe maternal sepsis in the UK, 2011-2012: a national case-control study. PLoS Med. 2014; 11(7): e1001672, doi: 10.1371/journal.pmed.1001672, indexed in Pubmed: 25003759.

19. Chantry AA, Deneux-Tharaux C, Cans $C$, et al. GRACE study group. Hospital discharge data can be used for monitoring procedures and intensive care related to severe maternal morbidity. J Clin Epidemiol. 2011; 64(9): 1014-1022, doi: 10.1016/j.jclinepi.2010.11.015, indexed in Pubmed: 21330103

20. Dennis AT, Solnordal CB. Acute pulmonary oedema in pregnant women. Anaesthesia. 2012; 67(6): 646-659, doi: 10.1111/j.1365-2044.2012.0705 5.x, indexed in Pubmed: 22420683.

21. Maternal mortality: Levels and trends 2000 to 2017 Authors: WHO, UNICEF, UNFPA, World Bank Group and the United Nations Population Division. https://www.who.int/reproductivehealth/publications/maternal-mortality-2000-2017/en/ (27.09.2020). 